Teresa Filipe*, Maria Moreno, Margarida Mota, Ciro Oliveira, António Bento Centro Hospitalar Psiquiátrico de Lisboa (CHPL), Portugal

\section{OBJECTIVES}

(1) To describe a case that presented to the CHPL inpatient clinic; (2) to present the evidence pertaining to the existence and the features of psychosis secondary to traumatic brain injury (TBI).

\section{BACKGROUND AND AIMS}

While evidence of an association between psychosis and TBI remains to be substantiated, distinguishing features between primary psychosis and psychosis following TBI have been identified.

\section{MATERIALS AND METHODS}

(1) Clinical chart review; (2) review of the literature through a Pubmed search with the syntax: (psychosis) AND ("trauma-induced psychosis" OR schizophrenia).

\section{TBI AND PSYCHIATRIC DISORDERS ${ }^{1}$}

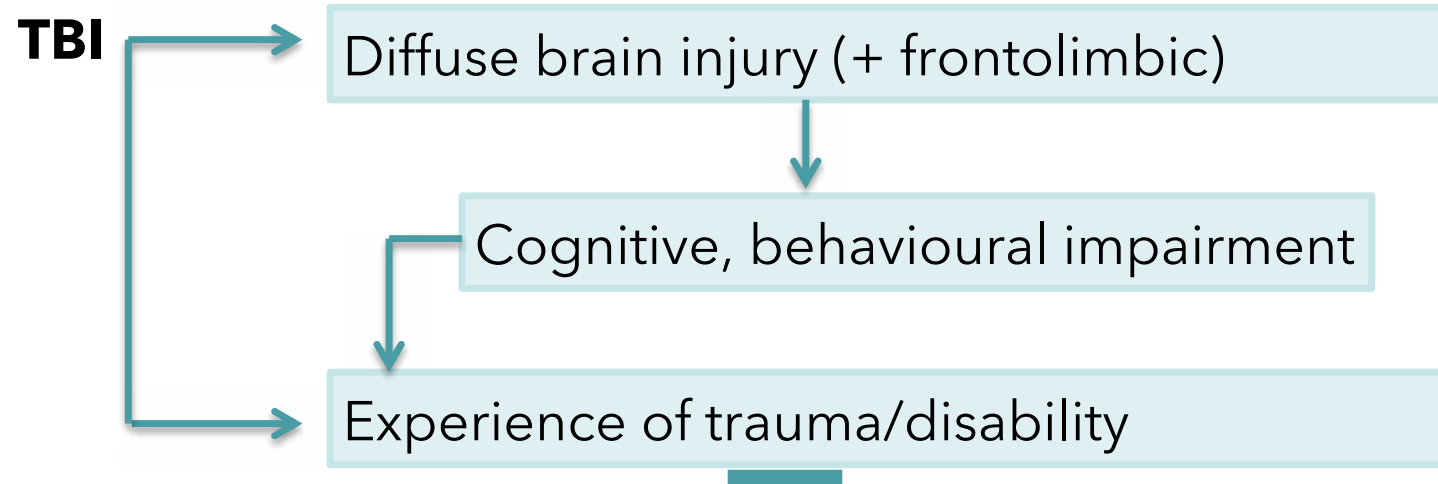

Circunstances, severity, injury location, preinjury psychosocial adjustment, postinjury support

Psychiatric disorders occur frequently after TBI.

\section{CASE REPORT}

Z.B., female, Ukrainian origin, works as a cleaning maid.

\section{Age}

17 TBI. No loss of consciousness or need for hospital admission.

25 While living in Argentina, where she had moved in search of better life conditions - imprecise feeling of unsafeness.

36 After her marriage, while living in Israel, she sustained another $\mathbf{T B I}$ with loss of consciousness and coma state.

She started believing that she was being monitored. For this reason, she moved back to Argentina and then to Portugal.

$1^{\text {st }}$ admission - religious, persecutory, thought control and broadcast delusions, misidentification phenomena, thirdperson derogatory auditory hallucinations and pressured speech.

46 2nd admission - similar clinical presentation;

MRI - T2-hyperintense lesion on the temporal lobe, determining local cortico-subcortical atrophy suggesting sequel lesion. No hemosiderin deposits. Blood work, chest $X$-ray and EEG were always unremarkable.

$3^{\text {rd }}$ admission - similar clinical presentation.

No history of manic or depressive symptoms

- No history of substance use;

- Previously medicated with haloperidol, amissulpride, valproic acid and clozapine without compliance;

- Good premorbid and reasonable interepisodic functioning

- Family history: uncle and grandmother with schizophrenia.

\title{
DIAGNOSTIC HYPOTHESES
}

(a) $\mathrm{TBI}$ and primary psychotic disorder are unrelated epiphenomena;

(b) TBI activated a preexisting psychotic proneness:

(c) TBI exacerbated a preexisting primary psychotic disorder.

TBI $\quad \cdot$ Rare $\quad$ Substantial disability $\quad$ Psychosis

Preinjury Psychotic Disorders not common 2 $(0 \%-4.3 \%)$

- Posttraumatic psychosis (vs idiopathic) : positive symptoms frequent + , negative symptoms -, temporal and frontal focal lesions, slowing in the EEG, cognitive impairement;

- Gradual onset, subacute/chronic course;

- Risk-modifying effect of TBI if genetic predisposition;;

- Meta-analysis : $\uparrow 60 \%$ in risk for schizophrenia after TBI ${ }^{4}$.
- PostTBI psychosis presentation relatively similar to idiopathic psychotic disorders ${ }^{5}$.

- Prospective studies: relatively low rates of psychotic disorders, consistent with population rates;

- Retrospective studies: relatively stable frequency of psychotic disorder with time after TBI. 